\title{
Characteristics, Effective Reproduction Number (Rt), and Prediction SIR Model of Covid-19 at Banyumas District, Central Java, Indonesia
}

\author{
Yudhi Wibowo ${ }^{1}$, Nendyah Roestijawati ${ }^{2}$, Siti Munfiah $^{3}$, Sadiyanto $^{4}$, Arif Burhanudin ${ }^{5}$, Misti Rahayu $^{6}$ \\ ${ }^{1}$ Assistant Professor in Department of Community Medicine, ${ }^{2}$ Assistant Professor in Department of Community \\ Medicine, ${ }^{3}$ Instructor in Department of Community Medicine, Faculty of Medicine, Jenderal Soedirman University, \\ Purwokerto, Indonesia, 53112, ${ }^{4}$ Practitioner and Staff, ${ }^{5}$ Practitioner and Staff 6. Practitioner and Staff at the \\ Banyumas District Health Office, Central Java
}

\begin{abstract}
Background: The Covid-19 pandemic has spread to 215 countries and territories since the outbreak first occurred in Wuhan, China. Indonesia has also declared the Covid-19 national disaster since 2 positive patients were found on March 2, 2020 and there has been a rapid spread to various regions in Indonesia including Banyumas District. This study aims to determine the risk factors, effective reproduction number and predictions SIR of Covid-19 in the Banyumas District for the period of 16 March - 14 June 2020.

Method: This study is a cross-sectional design. Cases are patients with comfirmed covid-19 in the area. Minimum sample size was 43 and total sample size was 70 people. Univariate analysis was used to describe of characteristics, epiestim to determine effective reproduction number, and SIR model to determine prediction of covid-19.

Result: As of June 14, 2020, in Banyumas District there were 392 suspected cases, 70 confirmed cases, 58 cases were recovered and 4 people died. The characteristics of the confirmed cases were the age group of $15-24$ years as much as $21.1 \%$, males $62 \%, 52.1 \%$ have a history of travel to/from out of town, and $91.5 \%$ showed symptoms especially fever symptoms as much as $81.7 \%$. The effective reproduction number (Rt) for the period March 16, 2020-June 14, 2020 was $1.81(0.83-3.35$; 95\% CrI). SIR model predictions, that the peak of the outbreak will occurred on June 21, 2020 with the number of confirmed cases of 4,312 people.

Conclusions: The covid-19 outbreak in Banyumas District was still out of control and still ongoing. It is recommended to continue to increase discipline of health protocols, get used to wearing masks, keep a distance and wash hands with soap and strengthen tests, traces and treatments and also protect vulnerable groups.
\end{abstract}

Keywords: Characteristics, effective reproduction number (Rt), SIR model of comfirmed covid-19, Banyumas District.

\section{Corresponding Author:}

\section{Dr. Yudhi Wibowo, M.Ph}

Department of Public Health \& Community Medicine

Department, Faculty of Medicine, Jenderal Soedirman University Purwokerto, Banyumas, Central Java, Indonesia, Jl. Dr. Gumbreg No. 1, Mersi, East

Purwokerto 53112

Phone: +62281-622022/08112621904

e-mail: dryudhiwibowo2005@gmail.com

\section{Introduction}

Corona virus disease-19 (covid-19) is an infectious disease caused by Severe Acut Respiratoty SyndromaCorona Virus-2 (SARS-CoV-2) formerly known as 2019-nCov. This disease originated from 41 cases of pneumonia without known cause in Wuhan, Hubei Province, China on December 30, 2019 and there is a history of contact with the seafood market. ${ }^{1-4}$ 
On March 11, 2020, WHO declared a global co-19 pandemic. This is because in the last 2 weeks there has been an increase in cases outside China 13 times and the number of affected countries increased 3 times. ${ }^{5,6} \mathrm{As}$ of May 5, 2020, the co-19 pandemic has spread to 215 countries and territories. Globally there were 3,525,116 confirmed covid-19 cases and 243,540 deaths. ${ }^{7}$

While in Indonesia as of May 6, 2020, there were 12,071 confirmed co-19s and 872 deaths. In Central Java, as of June 13, 2020 there were 2,066 positive and 147 people died and became the fourth epicenter after DKI Jakarta, East Java and West Java, ${ }^{8}$ while in Banyumas District there were 69 positive people and 4 people died. Characteristics of positive cases for a while as much as $60.6 \%$ are male and dominated by adolescents (10-19 years) as much as $16.7 \%$.

At present, most countries, including Indonesia, are preparing for a new normal life, as well as the Banyumas District. WHO has issued public health criteria to adjust public and social health measures in the context of covid-19. According to WHO, the covid-19 outbreak was controlled if $\mathrm{Rt}<1$ for at leat 2 weeks. ${ }^{9}$ This study aims to determine the characteristics, effective reproduction number \& prediction of the SIR model of Covid-19 disease in Banyumas District, Central Java.

\section{Method}

Research Design: This study was an observational analytic study using a cross-sectional design i.e. retrieval data and risk factors are carried out at one time. This study also uses Epiestim software to calculate the number of reproductive effecives and computer equipment to calculate the prediction of the SIR covid-19 outbreak model in Banyumas District.

Research Subjects: The population of this study was sourced from secondary data from the Banyumas District Health Office for the period March 16 to June 14, 2020. Suspect cases were cases that meet the criteria for suspicion according to WHO. Confirmation cases were cases with positive PCR results. ${ }^{10}$

The sample size was determined based on the significance level of 0.05 , the strength of the test $80 \%$, the proportion $\mathrm{p}=\mathrm{q}=0,5$, obtained a sample size of at least 43 people and in this study the total sample size was 71 comfirmed cases and 392 suspected cases.
Data Collection: The data was sourced from secondary data collected by the Banyumas District Health Office for the period March 16 to June 14, 2020. These data were the results of a survey containing names, addresses, age, sex, date of onset, symptoms and signs as well as travel history from/to outside city.

Effective Reproduction Number (Rt): The effective reproduction number (Rt) is an important parameter to find out whether outbreak control is effective or additional interventions are needed. ${ }^{11} \mathrm{Rt}$ values represent the number of new secondary cases that are infected from one infective case at time $t$. If $\mathrm{Rt}>$ 1 , the possibility of disease will become epidemic, if $\mathrm{Rt}=1$, the disease becomes endemic and if $\mathrm{Rt}<1$, the possibility of disease will disappear from circulation. ${ }^{12}$

To calculate the Rt in this study using EpiEstim software based on Excel developed by Cori et al in $2013^{13}$ and corrected by Thomson et al in $2019^{14}$. The mean serial interval (SI) and standard deviation (SD) using the results of the study of Tindale et al, namely the average $\mathrm{SI}=4.56$ and $\mathrm{SD}=0.95 .^{15}$

Prediction SIR Model: The SIR model as the initial formula that has been formulated by Kermack and McKendrick ${ }^{16}$ is a differential systemS (t); I (t); R (t); $\gamma$ $>0$ :

$$
\begin{aligned}
& \mathrm{St}=-\mathrm{SI} ; \\
& \mathrm{It}=\mathrm{SI}-\gamma \mathrm{I} ; \\
& \mathrm{Rt}=\gamma \mathrm{I} ;
\end{aligned}
$$

The interpretation of this model is very easy. The Susceptible individual population decreases through interaction with infective people, whose numbers increase through this mechanism. On the other hand, the population of infective individuals decreases because some individuals recover or die, and thus fill the Recover class. This epidemic model is known as the Susceptible, Infective, and Recover/Removed (SIR) epidemic model. The SIR model is very useful for predicting the future, end and peak of epidemics and other activities related to epidemic diseases. ${ }^{17}$

In this study, $\mathrm{R}=$ number of patients who recovered + who died. The description of the SIR model for Recover returning to Susceptible because the world outbreak of COVID-2019 has developed that patients who recover can be re-infected. ${ }^{18}$ 
$\mathrm{S}$ in this study is based on the estimated number of people who should be examined according to WHO standards of $1 / 1000$ population per week. ${ }^{19}$ During the period of March 16 to June 14, 2020 (13 weeks), the population of Banyumas District was 1,840,152 people, so $1,840 \times 13=23,922$ people as Suspected (S).

Data Analysis: Secondary data were analyzed to describe the characteristics of confirmed cases according to age group, sex, travel history to/from out of town, symptoms and signs. Rt was analyzed using EpiEstim to obtain median Rt and 95\% CrI. The prediction of the SIR model with computer software was analyzed to determine the prediction of the outbreak peak and the end of the covid-19 outbreak in Banyumas District.

Ethical Clearance: This study was approved by the Commission on Health Research Ethics, Medical School, Jenderal Soedirman University (Unsoed) with Ref no: 151/KEPK/VI/2020.

\section{Results}

Banyumas District is one of the districts in Central Java, Indonesia. Banyumas District consists of 27 sub-districts and 331 villages/outlands with an area of 132,759 hectares and a population of $1,840,152$ people. During the period from March 16 to June 14, 2020, there were 392 suspected cases, 71 confirmed cases, 58 cases were recovered and 4 cases died due to covid-19. Characteristics of 71 confirmed cases when first treated, are presented in Table 1.

Table 1. Characteristics of Comfirmed Covid-19 Cases

\begin{tabular}{|c|l|c|c|}
\hline \multicolumn{2}{|l|}{ Characteristics } & n & \% \\
\hline $\mathbf{1}$ & Age Group (year) & \multicolumn{2}{c|}{} \\
\hline & $0-<5$ & 2 & 2.8 \\
\hline & $5-14$ & 5 & 7.0 \\
\hline & $15-24$ & 15 & 21.1 \\
\hline & $25-34$ & 10 & 14.1 \\
\hline & $35-44$ & 10 & 14.1 \\
\hline & $45-54$ & 8 & 11.3 \\
\hline & $55-64$ & 11 & 15.5 \\
\hline & $65-74$ & 5 & 7.0 \\
\hline & $75-84$ & 5 & 7.0 \\
\hline & $>84$ & 0 & 0 \\
\hline
\end{tabular}

\begin{tabular}{|c|c|c|c|}
\hline \multicolumn{2}{|r|}{ Characteristics } & $\mathbf{n}$ & $\%$ \\
\hline 2 & \multicolumn{3}{|l|}{ Gender } \\
\hline & Male & 44 & 62.0 \\
\hline & Female & 27 & 38.0 \\
\hline \multirow[t]{3}{*}{3} & \multicolumn{3}{|l|}{ Travel history } \\
\hline & Yes & 37 & 52.1 \\
\hline & Not & 34 & 47.9 \\
\hline \multirow[t]{12}{*}{4} & \multicolumn{3}{|l|}{ The symptoms } \\
\hline & Yes & 65 & 91.5 \\
\hline & Fever & 58 & 81.7 \\
\hline & Cough & 33 & 46.5 \\
\hline & Flu & 4 & 5.6 \\
\hline & Sore throat & 1 & 1.4 \\
\hline & Headache & 1 & 1.4 \\
\hline & Malaise & 1 & 1.4 \\
\hline & Nauseous vomit & 1 & 1.4 \\
\hline & No appetite & 1 & 1.4 \\
\hline & Dyspneu & 4 & 5.6 \\
\hline & Not & 6 & 8.5 \\
\hline \multirow[t]{8}{*}{5} & Death & 4 & 5.6 \\
\hline & \multicolumn{3}{|l|}{ Age group (year) } \\
\hline & $45-54$ & 2 & 50,0 \\
\hline & $55-64$ & 1 & 25.0 \\
\hline & $75-84$ & 1 & 25.0 \\
\hline & \multicolumn{3}{|l|}{ Gender } \\
\hline & Male & 2 & 50.0 \\
\hline & Female & 2 & 50.0 \\
\hline
\end{tabular}

According to Table 1, the 15-24 years age group most suffering from covid-19 were $21.1 \%, 62 \%$ were male, $52.1 \%$ had a history of travel to/from out of town and $91.5 \%$ showed symptoms with main symptoms were fever (81.7\%) and cough (46.5\%).Cases that have died amounted to 4 people or a mortality rate of $5.6 \%$ with the age of 45 years and over and have comorbid diseases. Effective reproduction number (Rt) for the period March 16 to June 14,2020 , obtained $\mathrm{Rt}=1.81(0.83-3.35 ; 95 \%$ $\mathrm{CrI}$ )as shown in Figure 1. In the past 14 days, the trend of Rt can be seen in Table 2 . 
$\mathrm{R}$ averaged over time periods (posterior median and $95 \% \mathrm{Crl}$ )

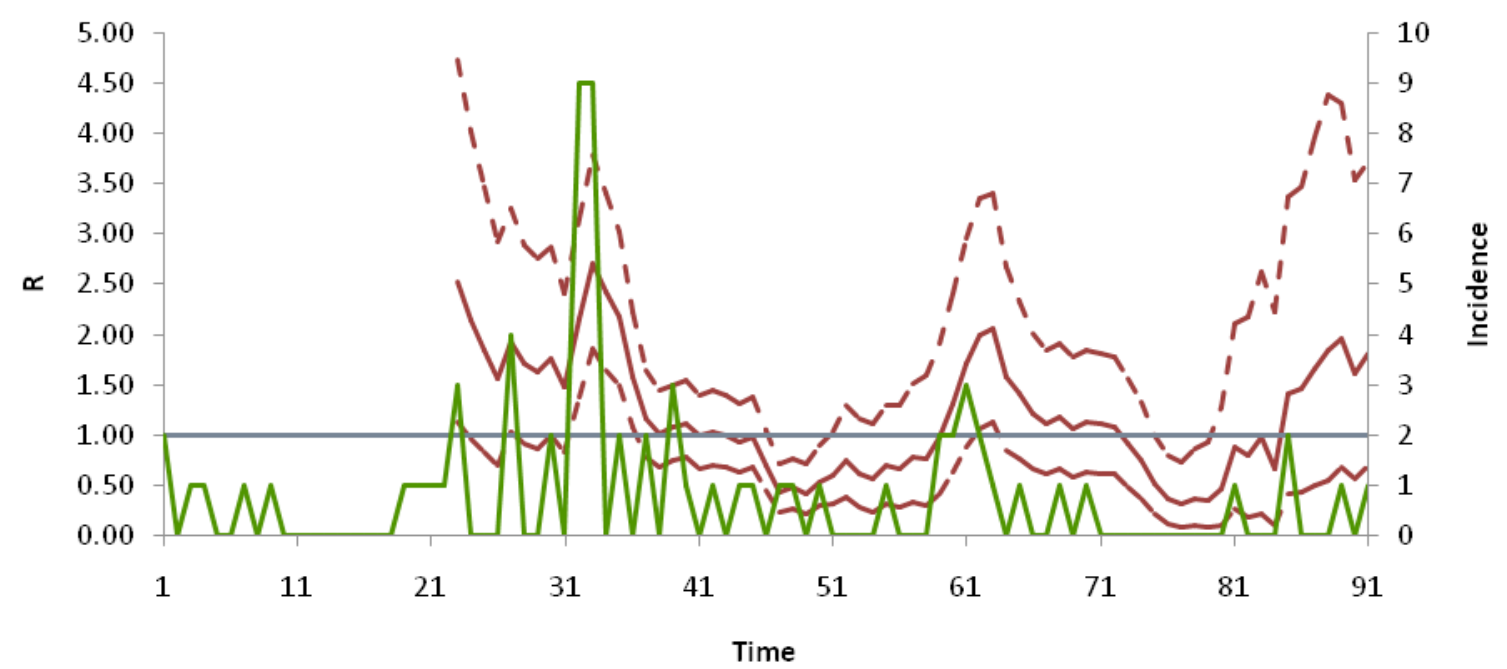

$R$ (median) _ - - R (95\% credible interval $)$

$\mathrm{R}=1$

Incidence

Figure 1. Trends of Effective Reproductive Number (Rt) of Covid-19 in Banyumas District, Period March 16 to June 14, 2020

Table 2. Trends of effective reproductive numbers (Rt) of covid-19 for the last 14 days

\begin{tabular}{|c|l|c|c|c|}
\hline No. & Date & $\mathbf{0 , 0 5} \mathbf{Q}$ & $\mathbf{M}$ & $\mathbf{0 , 9 5} \mathbf{Q}$ \\
\hline 1 & $01-J u n-20$ & 0,14 & 0,36 & 0,77 \\
\hline 2 & $02-J u n-20$ & 0,1 & 0,34 & 0,81 \\
\hline 3 & $03-J u n-20$ & 0,15 & 0,47 & 1,12 \\
\hline 4 & $04-J u n-20$ & 0,33 & 0,89 & 1,87 \\
\hline 5 & $05-J u n-20$ & 0,25 & 0,8 & 1,9 \\
\hline 6 & $06-J u n-20$ & 0,3 & 0,97 & 2,29 \\
\hline 7 & $07-J u n-20$ & 0,14 & 0,67 & 1,89 \\
\hline 8 & $08-J u n-20$ & 0,52 & 1,41 & 2,97 \\
\hline 9 & $09-J u n-20$ & 0,54 & 1,45 & 3,07 \\
\hline 10 & $10-J u n-20$ & 0,62 & 1,66 & 3,51 \\
\hline 11 & $11-J u n-20$ & 0,68 & 1,84 & 3,88 \\
\hline 12 & $12-J u n-20$ & 0,83 & 1,96 & 3,84 \\
\hline 13 & $13-J u n-20$ & 0,68 & 1,61 & 3,15 \\
\hline 14 & $14-J u n-20$ & 0,83 & 1,81 & 3,35 \\
\hline
\end{tabular}

According to Table 2, Rt Covid-19 from 1-14 June 2020 (last 14 days) still obtained Rt $<1$ but upper bond $>1 \&$ Rt $>1$ (red color). The Covid-19 outbreak in
Banyumas District was predicted for the next 100 days from June 14, 2020 with the SIR model and the results are presented in Figure 2 and Table 3. 


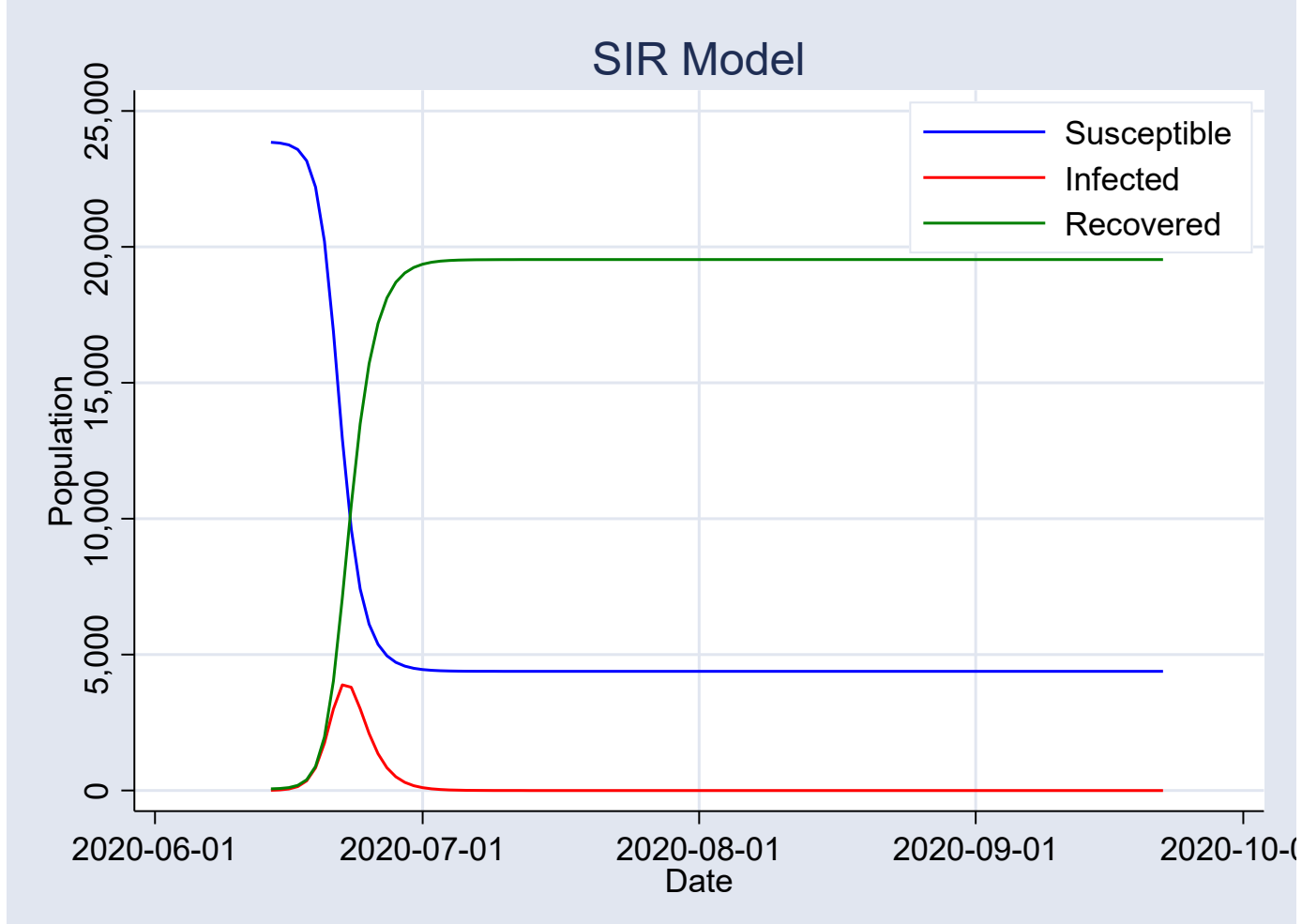

Figure 2. SIR Model of Covid-19 Outbreak in Banyumas District

Table 3. SIR Model of the Peak and end of Covid-19 Outbrek

\begin{tabular}{|l|c|c|c|}
\hline Population & $\mathbf{2 0 2 0 - 0 6 - 1 4}$ & $\mathbf{2 0 2 0 - 0 6 - 2 2}$ & $\mathbf{2 0 2 0 - 0 9 - 2 2}$ \\
\hline Susceptible & 23,848 & 12,948 & 4,348 \\
\hline Infected & 9 & 3,886 & 0 \\
\hline Recovered & 62 & 7,083 & 19,534 \\
\hline Total & $\mathbf{2 3 , 9 1 8}$ & $\mathbf{2 3 , 9 1 8}$ & $\mathbf{2 3 , 9 1 8}$ \\
\hline
\end{tabular}

\section{Discussion}

The 15-24 years age group is the highest group suffering from confirmed covid-19 cases in Banyumas Districs. It is appropriate that coivd-19 can affect all ages. ${ }^{20}$ Specifically, in Banyumas District, this age group is related to school-age children where at the beginning of the outbreak, no action has yet been taken to close the learning process at school. Some schools even have study tours outside the city. Of course, this increases the risk of covid-19 transmission. There were $52.1 \%$ of confirmed cases have a history of travel from/ out of town and certainly increase the risk of covid-19 transmission. $^{21}$

The comfirmed covid-19 cases were $62 \%$ male. Covid-19 sufferers are mostly male, this is associated with the possibility of men smoking more, and women have protection from the $\mathrm{X}$ chromosome and sex hormones which play an important role in innate immunity and adaptation. ${ }^{22-24}$

There were 4 cases of death (mortality rate $5.6 \%$ ) due to covid-19 and age 45 years or more and had comorbid disease. Old age and the presence of chronic comorbid diseases can increase the fatality of covid-19 disease. Although the covid-19 fatality rate at the age of 80 years or more between China and Italy is the same. ${ }^{22,25}$ According to the Centers for Disease Control and Prevention (CDC) the age group ( $\geq 65$ years) and all ages with comorbid diseases such as chronic lung disease, moderate-severe asthma, heart disease, immunocompromis (cancer treatment, smoking, organ transplantation or bone marrow, immune deficiency, uncontrolled HIV/AIDS, prolonged use of corticosteroids, and other treatments that weaken 
the immune system), severe obesity, diabetes mellitus, chronic kidney disease, and liver disease, increase the risk of suffering from severe covid-19. ${ }^{20}$

The effective reproduction number (Rt) in the last 14 days, namely June 1, 2020 to June 14, 2020, is obtained Rt $>1 .{ }^{9}$ Predictions with the SIR model that the peak of the outbreak will occur on June 22, 2020 with the number of cases as many as 3,886 and the outbreak will subside on September 22, 2020. This indicates that the covid-19 outbreak in Banyumas Districs has not been controlled. Therefore, efforts to increase discipline on health protocols, to get used to using masks, keep a distance from others at least 1-2 meters and wash hands with soap. contact tracing, testing and treatment continue to be improved and protect vulnerable groups.

\section{Conclusions}

The covid-19 outbreak in Banyumas Districs is still not controlled. Therefore, it is still necessary to remain disciplined about health protocols and other prevention efforts. Tracing contacts, testing and treatment continues to be strengthened while still protecting vulnerable groups.

Conflict of Interest: The authors declare that they have no competing interests.

Acknowledgment: Thank you to the Jenderal Sudirman University, The Institute for Research and Community Service, Faculty of Medicine, Banyumas District Health Office and Community Health Care for their cooperation and assistance.

Source of Funding: This research was independently funded.It was a collaboration between the Faculty of Medicine, Jenderal Soedirman University and the Banyumas District Health Office, Central Java.

\section{References}

1. WHO. Coronavirus [Internet]. Genewa: WHO; 2020. p. tab1. Available from: https://www.who. int/health-topics/coronavirus\#tab=tab_1

2. WHO. Naming the coronavirus disease (COVID-19) and the virus that causes it. World Heal Organ [Internet]. 2020; Available from: https://www.who.int/emergencies/diseases/novelcoronavirus-2019/technical-guidance/naming-thecoronavirus-disease-(covid-2019)-and-the-virusthat-causes-it
3. Isaac I. Bogoch, Alexander Watts, Andrea ThomasBachli, Carmen Huber MUGK and KK. Pneumonia of unknown aetiology in Wuhan, China: potential for international spread via commercial air travel. J Travel Med [Internet]. 2020; Available from: https://doi.org/10.1093/jtm/\%0Ataaa008

4. $\mathrm{Lu} \mathrm{H}$, Stratton CW, Tang YW. Outbreak of pneumonia of unknown etiology in Wuhan, China: The mystery and the miracle [Internet]. Journal of Medical Virology. 2020. Available from: https:// doi.org/10.1002/jmv.25678

5. Sohrabi C, Alsafi Z, O'Neill N, Khan M, Kerwan A, Al-Jabir A, et al. World Health Organization declares global emergency: A review of the 2019 novel coronavirus (COVID-19). International Journal of Surgery. 2020.

6. Cucinotta D, Vanelli M. WHO declares COVID-19 a pandemic. Acta Biomedica. 2020.

7. WHO. Coronavirus disease [Internet]. Vol. 2019, World Health Organization. 2020. p. 2633. Available from: https://www.who.int/emergencies/ diseases/novel-coronavirus-2019

8. Kemenkes R. Situasi Terkini Perkembangan Coronavirus Disease (COVID-19) 5 Mei 2020 [Internet]. Jakarta; 2020. Available from: https:// covid19.kemkes.go.id/situasi-infeksi-emerging/ info-corona-virus/situasi-terkini-perkembangancoronavirus-disease-covid-19-5-mei-2020/\#. XrJDKKgzbIU

9. World Health Organisation. Considerations in adjusting public health and social measures in the context of COVID-19. World Heal Organ [Internet]. 2020;(May):1-7. Available from: https://www. who.int/publications-detail/risk-

10. WHO. World Health Organization. Global Surveillance for human infection with coronavirus disease (COVID-19). Interim Guid [Internet]. 2020;(February):27-9. Available from: https:// www.who.int/publications-detail/globalsurveillance-for-human-infection-with-novelcoronavirus-(2019-ncov)

11. Nishiura H, Chowell G. The effective reproduction number as a prelude to statistical estimation of timedependent epidemic trends. In: Mathematical and Statistical Estimation Approaches in Epidemiology. 2009.

12. Camacho A, Kucharski A, Aki-Sawyerr Y, White MA, Flasche S, Baguelin M, et al. Temporal 
changes in ebola transmission in sierra leone and implications for control requirements: A real-time modelling study. Vol. 7, PLoS Currents. 2015.

13. Cori A, Ferguson NM, Fraser C, Cauchemez S. Package 'EpiEstim' July. American Journal of Epidemiology. 2013.

14. Thompson RN, Stockwin JE, van Gaalen RD, Polonsky JA, Kamvar ZN, Demarsh PA, et al. Improved inference of time-varying reproduction numbers during infectious disease outbreaks. Epidemics. 2019;

15. Tindale L, Coombe M, Stockdale JE, Garlock E, Lau WYV, Saraswat M, et al. Transmission interval estimates suggest pre-symptomatic spread of COVID-19. medRxiv. 2020;

16. W. O. Kermack and A. G. McKendrick. A contribution to the mathematical theory of epidemics. In: Proceedings of the Royal Society of London Series A, Containing Papers of a Mathematical and Physical Character. 1927.

17. Hethcote HW. Mathematics of infectious diseases. SIAM Rev. 2000;

18. Yadav DRS. Mathematical Modeling and Simulation of SIR Model for COVID-2019 Epidemic Outbreak: A Case Study of India. medRxiv. 2020;

19. World Health Organization. Considerations for public health and social measures in the workplace in the context of COVID-19. World Heal Organ
[Internet]. 2020;(May):1-7. Available from: https:// www.who.int/publications-detail/risk-

20. Centers for Disease Control and Prevention. People who are at higher risk for severe illness | CDC [Internet]. Centers for Disease Control and Prevention. 2020. Available from: https:// www.cdc.gov/coronavirus/2019-ncov/needextra-precautions/people-at-higher-risk. html?CDC_AA_refVal=https $\% 3 \mathrm{~A} \% 2 \mathrm{~F} \% 2 \mathrm{Fwww}$. c d c.gov\% 2 F c oronavirus \% 2 F 2019 ncov\%2Fhcp\%2Funderlying-conditions.html

21. Bi Q, Wu Y, Mei S, Ye C, Zou X, Zhang Z, et al. Epidemiology and Transmission of COVID-19 in Shenzhen China: Analysis of 391 cases and 1,286 of their close contacts. medRxiv. 2020;

22. Chen N, Zhou M, Dong X, Qu J, Gong F, Han Y, et al. Epidemiological and clinical characteristics of 99 cases of 2019 novel coronavirus pneumonia in Wuhan, China: a descriptive study. Lancet. 2020;

23. Cai H. Sex difference and smoking predisposition in patients with COVID-19. The Lancet Respiratory Medicine. 2020.

24. Jaillon S, Berthenet K, Garlanda C. Sexual Dimorphism in Innate Immunity. Clinical Reviews in Allergy and Immunology. 2019.

25. Onder G, Rezza G, Brusaferro S. Case-Fatality Rate and Characteristics of Patients Dying in Relation to COVID-19 in Italy. JAMA - Journal of the American Medical Association. 2020. 